International Journal of Mechanical Engineering and Technology (IJMET)

Volume 12, Issue 2, February 2021, pp. 25-34. Article ID: IJMET_12_02_003

Available online at https://iaeme.com/Home/issue/IJMET? Volume=12\&Issue=2

ISSN Print: 0976-6340 and ISSN Online: 0976-6359

DOI: https://doi.org/10.34218/IJMET.12.2.2021.003

C IAEME Publication

Scopus Indexed

\title{
DECAY CHARACTERISTICS OF OGIVAL GROOVED SUPERSONIC NOZZLE: AN EXPERIMENTAL INVESTIGATION
}

\author{
A Shankar* \\ Assistant Professor, Department of Aeronautical Engineering, Gojan School of Business and \\ Technology, Redhills, Chennai, Tamil Nadu, India. \\ K Krishnakumar \\ Lecturer, Ibri College of Technology, Oman
}

\section{S Ramu}

Assistant Professor, Department of Mechanical Engineering, Gojan School of Business and Technology, Redhills, Chennai, Tamil Nadu, India.

R Srinivasan

Assistant Professor, Department of Mechanical Engineering, Gojan School of Business and Technology, Redhills, Chennai, Tamil Nadu, India.

*Corresponding Author

\begin{abstract}
This project reports an experimental investigation of jet decay characteristics experienced by grooved supersonic nozzle. The objective of the project is to optimize the jet noise and enhance the jet entrainment of the exhaust flow with the atmosphere by providing sudden expansion inside the chamber (divergent section) of the Supersonic $C$-D nozzle. Flow characteristics such as axial jet decay, radial jet decay at successive locations downstream and elevated core length are calculated experimentally and compared with those of a conventional $C$-D nozzle (Base line nozzle) under identical experimental conditions. The jet decay characteristics along the jet marked line for the grooved nozzle is to be compared to those of the conventional one. With better jet decay characteristics, it possesses shorter potential core length resulting in considerable reduction of jet noise.
\end{abstract}

Keywords: C-D Nozzle, Grooved Supersonic nozzle and Jet Decay. 
Cite this Article: A Shankar, K Krishnakumar, S Ramu and R Srinivasan, Decay Characteristics of Ogival Grooved Supersonic Nozzle: An Experimental Investigation, International Journal of Mechanical Engineering and Technology (IJMET), 12(2), 2021, pp.25-34.

https://iaeme.com/Home/issue/IJMET?Volume=12\&Issue=2

\section{INTRODUCTION}

In general Chevrons nozzle using to enhance the jet decay characteristics for mainly modification about chevrons, specification of chevron is irregular in shape like zigzag or raw tooth shapes at the end of the nacelle, with the end of the tips are in bent very slightly, and are being implemented on modern jet engines. The recent technology has elevated to reduction of turbulent mixing noise that is the separated device of jet noise for using aircraft. They are several models to establish mixing noise factor such as triangular cut outs, trapezoidal cut outs and winglets etc, made along the trailing edge of the nozzle induce stream-wise vortices into the shear layer leading to increased mixing and reduced jet plume length. Most innovative optimized design to increase the level of mixing noises to improve the jet decay characteristics.

This project focused about chevron nozzle design for reducing jet nozzle emission in exhaust nozzle of turbofan engine. Four different design and dimension estimated to reduce jet noise emission, they are plain nozzle, chevron triangular pattern, and chevron pedal pattern and modified triangular patterns. Significantly achieved acoustic power level reduces and velocity of exit nozzle increases in combining different chevron patterns. Especially chevron pattern modified triangular mode reduces the sound pressure level $27 \mathrm{~dB}$ and produce high velocity than other chevron models [1]. Experimental analysis were done by CATIA, ICEM CFD and ANSYS CFX software. The supersonic jet nozzle model generated in variety of dimensions like triangular internal grooves, circular jet with and without grooves, single groove and with two grooves. By comparing these model identified grooves act as effective passive control significantly enhanced the jet mixing. Mach No. to total pressure based on the grove length by increasing and the decay characteristic also improved [2]. This project concentrated corrugated plate $115^{\circ}$ located near the chevron trailing edge at nozzle exit. The rate of fluid flow mixing at the end of nozzle increased because of located near to corrugated plate [3]. Experimental work planned to improve the effect of internal groove cut along with selected Mach no. 1.8 between that converging- diverging nozzle. Section design at the exit nozzle were prepared from plain nozzle, semicircular groove nozzle, two square groove. Prepared design rated about the nozzle authentication described the shock cell structure of grooved nozzle is weaker than the plain nozzle [4]. Designed divergent-convergent nozzle Mach no. 1.4 with exit nozzle diameter $12 \mathrm{~mm}$, four different models were experimented among the design truncated square model nozzle achieved maximum velocity decay characteristic also improved. Identified core length reduced in one groove, two groove were reduced under expansion. Finalized the two groove model is more effective than the one groove model [5]. This paper studies the function of chevrons by comparing different chevrons orientations such as placing the chevrons on primary flow, on secondary flow, on both primary and secondary flow. Chevrons are gas dynamic equipment's which by creating vertical flow, enables efficient mixture of two flows with different velocities, thereby reducing the resultant noise of the flow interaction [6].

\section{EXPERIMENTAL DESIGN \& SETUP}

\subsection{Design of Convergent-Divergent Nozzle with Ogival Grooves}

A nozzle is a tube of varying cross- sectional area are commonly represented the axis made axisymmetric geometry focusing to increasing the speed of outward flow and then controlling its direction and flow shape. C-D nozzle with a special type of ogival grooves is adopted in this 
project. Diagrammatic solution observe through CATIA software to make wireframe design, styling, surfacing workflow and visualization to create, modify, and validate complex innovative shapes from industrial design to class-A surfacing with the ICEM surfacing technologies.

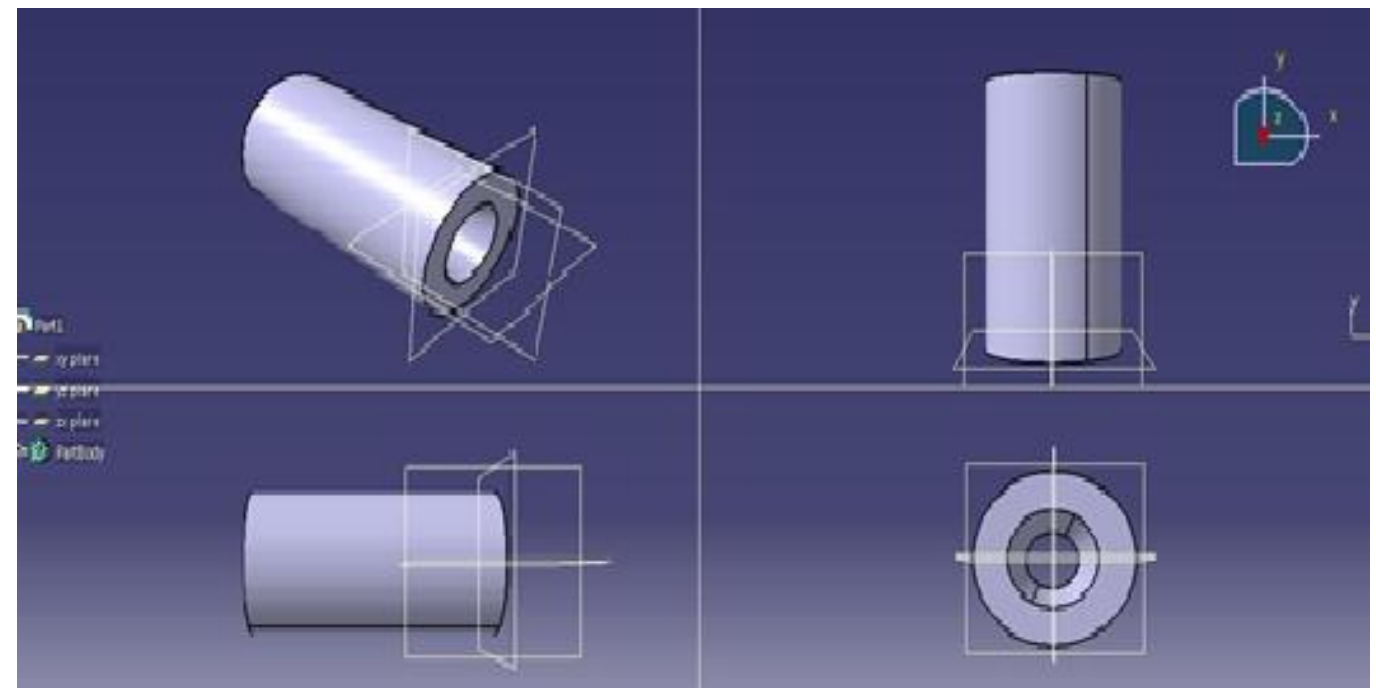

Figure 1 Four view diagram of the conventional nozzle

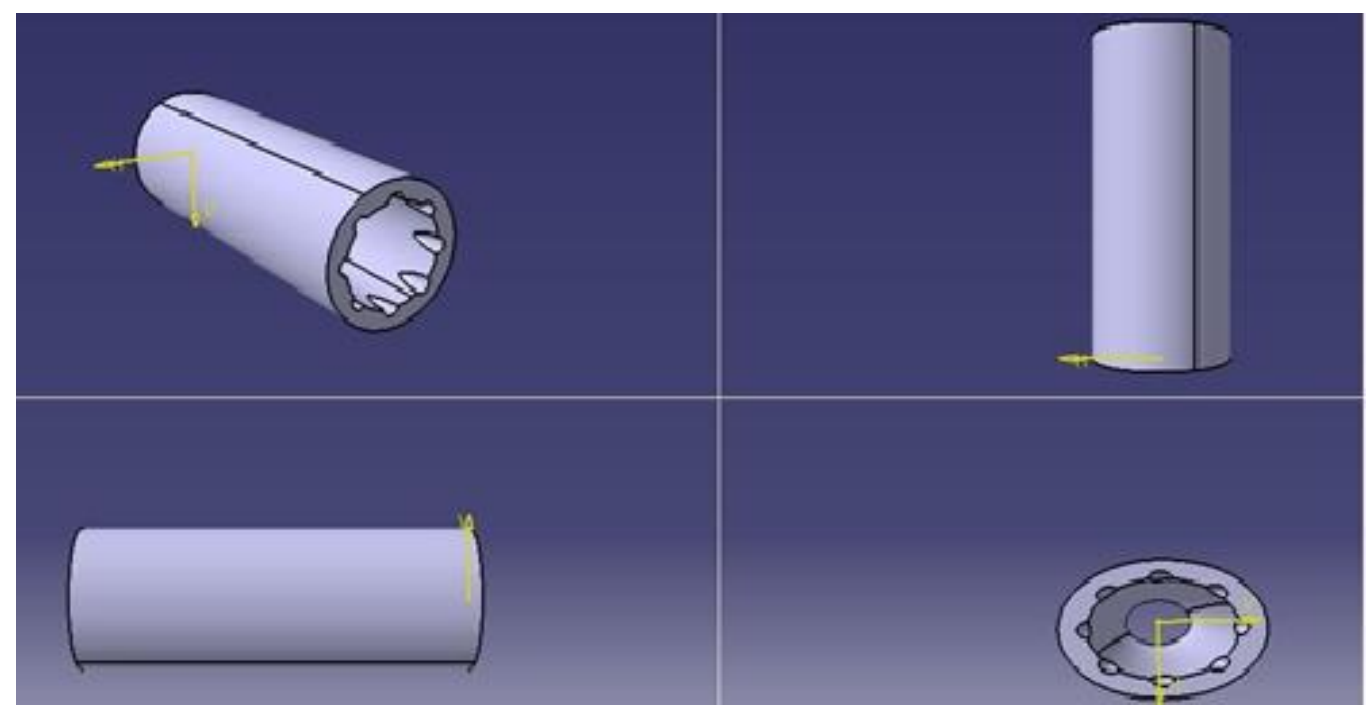

Figure 2 Four view diagram of the grooved nozzle

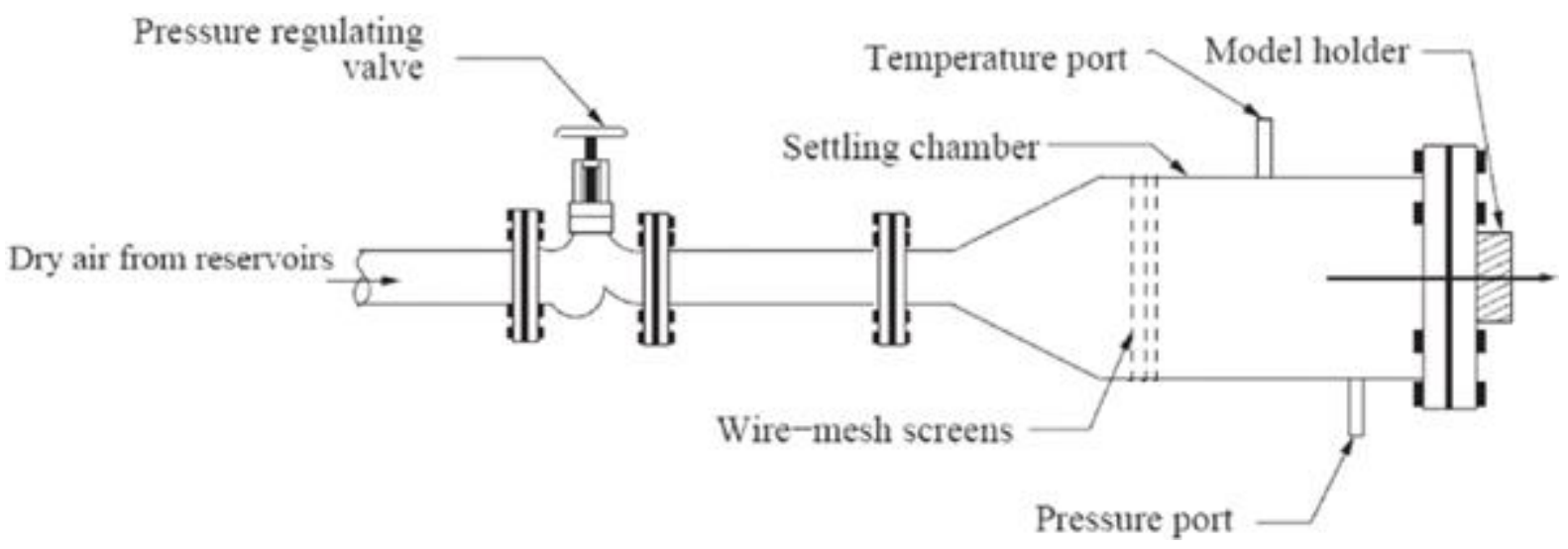

Figure 3 Schematic diagram of a free jet test facility 
Analyzing a jet are the centerline pressure or velocity decay and pressure or velocity profiles. These are done using the pitot pressure measured along the jet axis and across the jet in the direction normal to the jet axis. It is usual practice to use the measured pitot pressure data to study the decay and spread characteristics of supersonic jets. From these plots, the vital characteristics of the jet namely, the core length, characteristic decay, spread of the jet can be discerned. The jet noise is another important parameter to be considered in the study of high speed jets. For subsonic jets, in addition to the mixing noise, the shock associated noise can contribute significantly to the overall jet noise.

\section{EXPERIMENTAL CONDITIONS}

The experiment was carried out with a settling chamber pressure of $2.4 \mathrm{~kg} / \mathrm{Cm}^{2}$. The room temperature was maintained at $32^{\circ} \mathrm{C}$.

$$
\frac{P_{t}}{P}=\left(1+\frac{\gamma-1}{2} M^{2}\right)^{\frac{\gamma}{\gamma-1}}
$$

The Mach number was set to be 1.2. The pitot probe was fixed at the center of the exit plane (origin) for the initial reading and moved in all three directions with the help of the traversing mechanism.

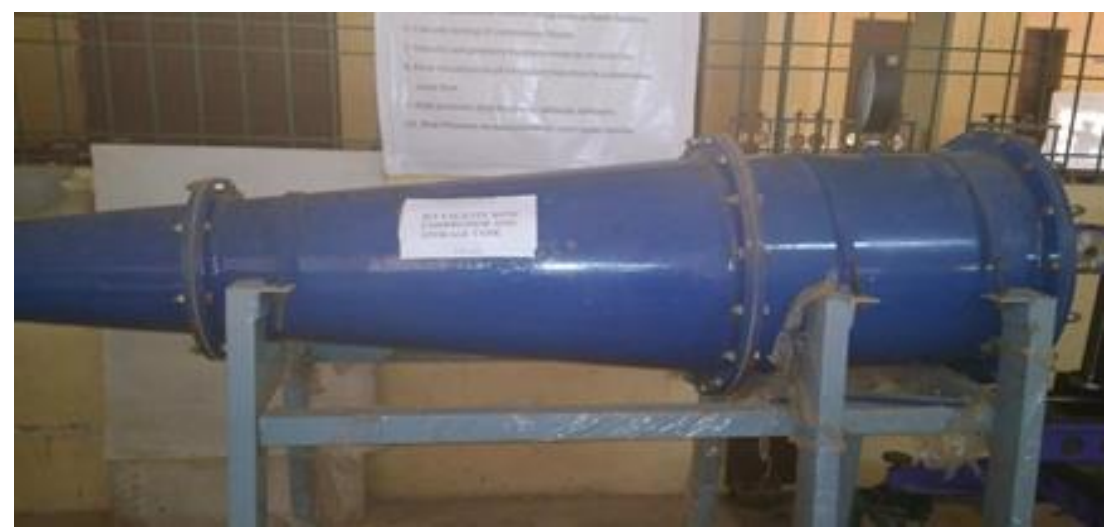

Figure 4 Settling chamber

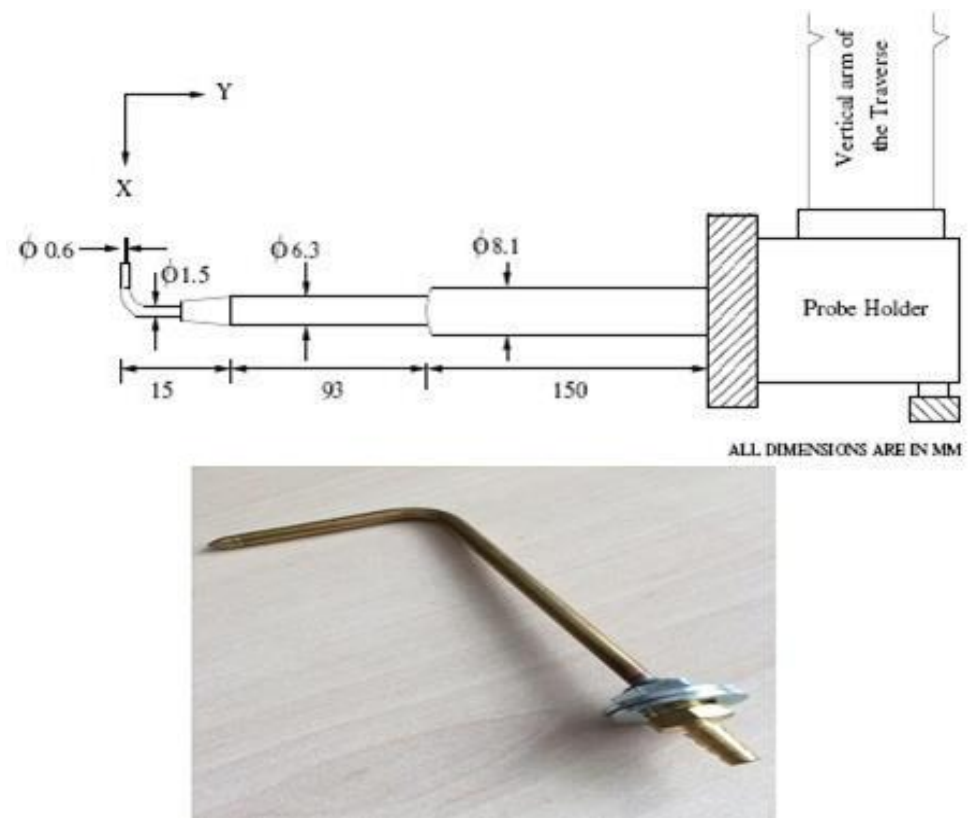

Figure 5 Schematic diagram \& Pitot probe 
Settling chamber pressure, $\mathrm{P}_{\mathrm{o}}$ or $\mathrm{P}_{\mathrm{t}}=2.4 \mathrm{~kg} / \mathrm{cm}^{2}=3.366846$ bar Static pressure, $\mathrm{P}=1.36325$ bar

$$
\begin{aligned}
\mathrm{P}_{\mathrm{o}} / \mathrm{P} & =2.469 \\
& =1.4
\end{aligned}
$$

(Isentropic Mach number relation) Using this relation the Mach number is found to be 1.21. The same settling chamber pressure is used for both the conventional and grooved nozzle.
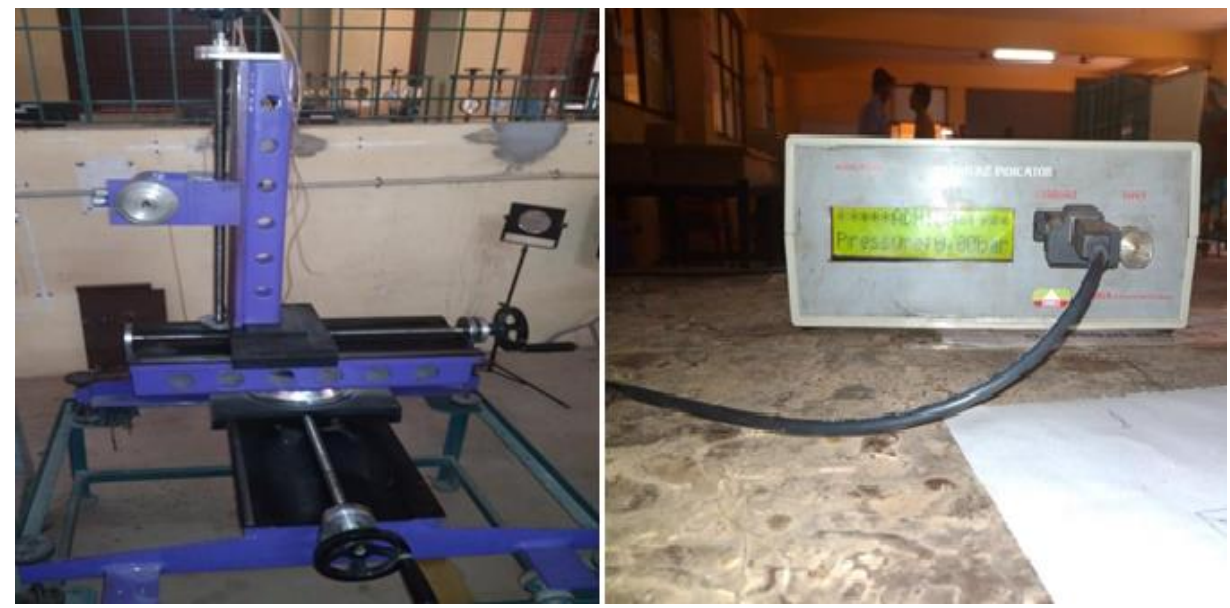

Figure 6 Traversing mechanism \& Pressure transducer

\section{RESULTS AND DISCUSSION}

\subsection{Conventional Nozzle}

Fig. 7 gives the plot between pressure ratio $\mathrm{P}_{\mathrm{o}} / \mathrm{P}$ and $\mathrm{X} / \mathrm{D}$ of the conventional nozzle. It shows the axial pressure decay of the nozzle in the $\mathrm{X}$ direction. The peak point of the pressure ratio is found at the exit plane and decreases gradually to reach the saturation point at $0.875 \mathrm{D}$, which is therefore found to be the potential core length of the conventional nozzle. The amount of turbulent interaction in potential core region is the main the source of jet noise. Any reduction in the potential core length will directly result in reduction of jet noise.

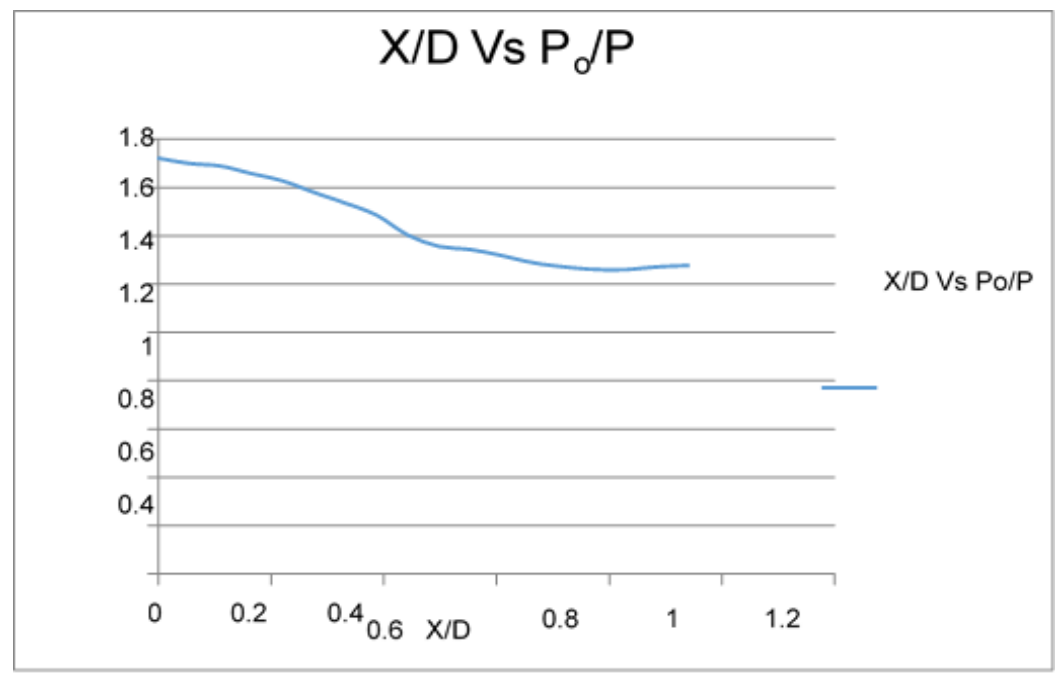

Figure 7 Axial pressure decay (X-Direction)

Fig. 8 gives the plot between pressure ratio $\mathrm{P}_{\mathrm{o}} / \mathrm{P}$ and $\mathrm{Y} / \mathrm{D}$ of the conventional nozzle. It shows the radial pressure decay of the nozzle in the $\mathrm{Y}$ direction. The pressure ratio increases from a minimal value to reach its optimum value inside the nozzle periphery at the centre of the 
exit plane and then tends to decrease thereafter. This result is obtained due to symmetric geometry of conventional nozzle

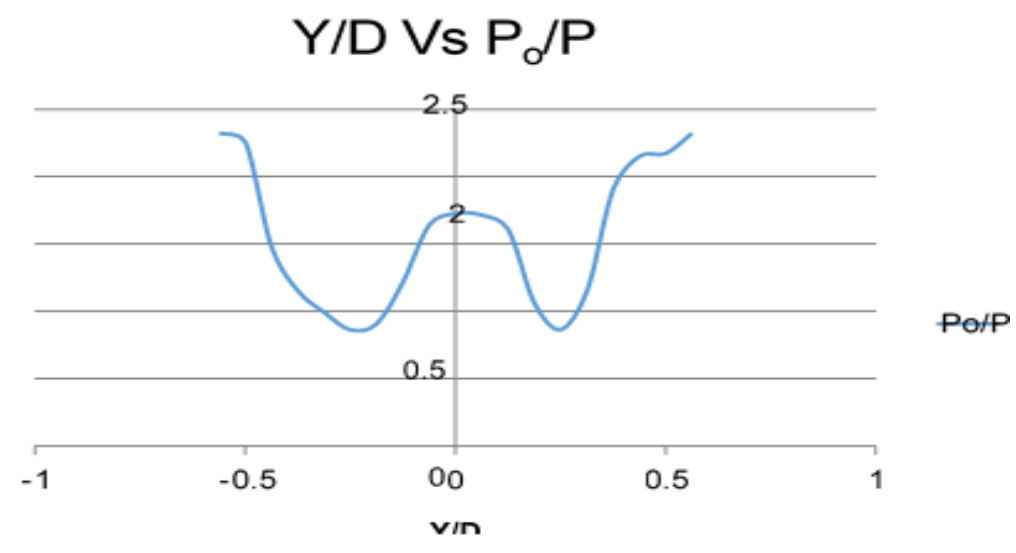

Figure 8 Radial pressure decay (Y Direction)

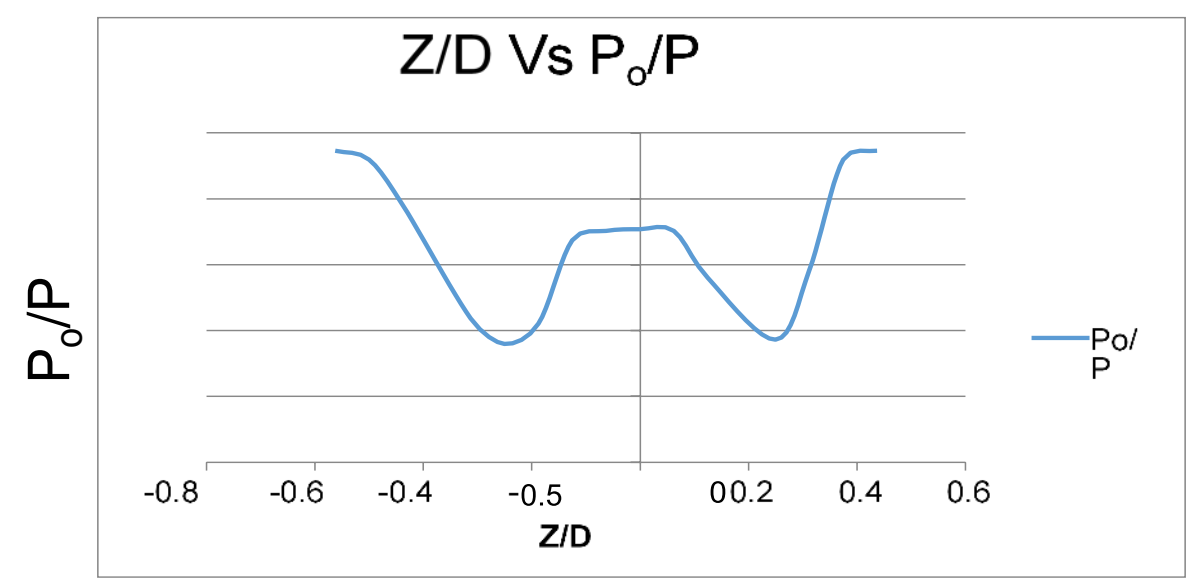

Figure 9 Radial pressure decay ( $\mathrm{Z}$ direction)

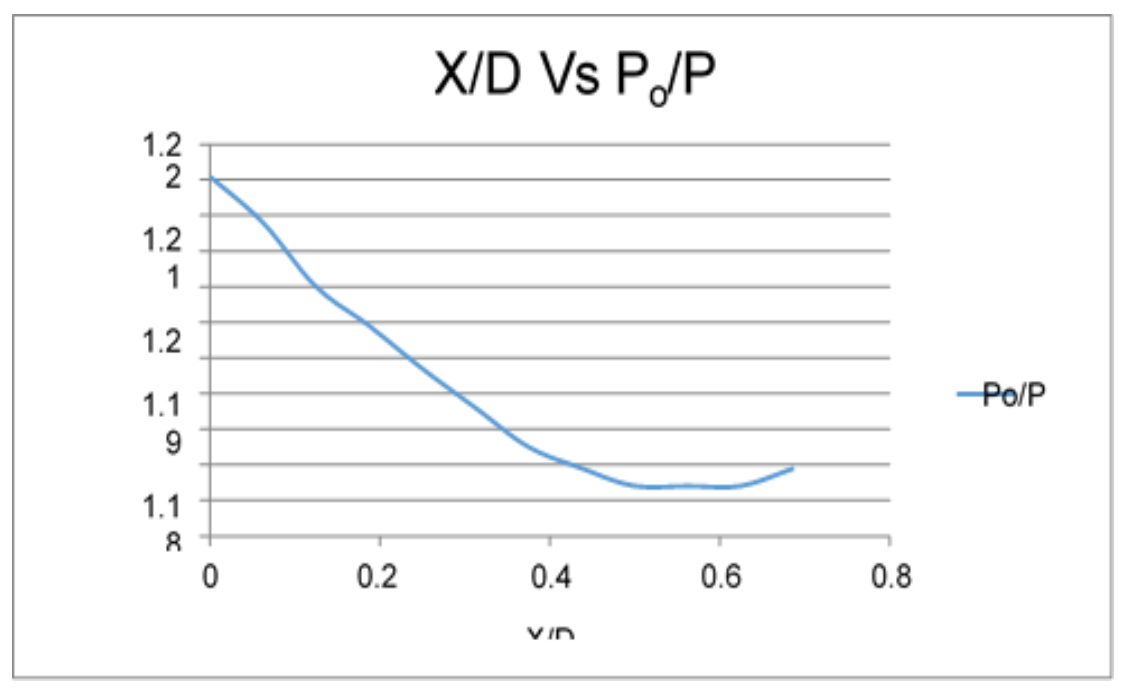

Figure 10 Axial pressure decay (X Direction)

Fig.9 gives the plot between pressure ratio $\mathrm{P}_{\mathrm{o}} / \mathrm{P}$ and $\mathrm{Z} / \mathrm{D}$ of the conventional nozzle. It shows the radial pressure decay of the nozzle in the $\mathrm{Z}$ direction. The pressure ratio increases from a minimal value to reach its optimum value inside the nozzle periphery at the centre of the exit 
plane and then tends to decrease thereafter. This result is obtained due to symmetric geometry of conventional nozzle.

\subsection{Grooved Supersonic Nozzle}

Fig. 10 gives the plot between pressure ratio $\mathrm{P}_{\mathrm{o}} / \mathrm{P}$ and $\mathrm{X} / \mathrm{D}$ of the grooved nozzle. It shows the axial pressure decay of the nozzle in the $\mathrm{X}$ direction. The peak point of the pressure ratio is found at the exit plane and decreases gradually to reach the saturation point at $0.5 \mathrm{D}$, which is therefore found to be the potential core length of the grooved nozzle.

Fig.11 gives the plot between pressure ratio Po/P and Y/D of the grooved nozzle. It shows the radial pressure decay of the nozzle in the $\mathrm{Y}$ direction. The pressure ratio increases from a minimal value to reach its optimum value inside the nozzle periphery at the centre of the exit plane and then tends to decrease thereafter. This result is obtained due to symmetric geometry of grooved nozzle.

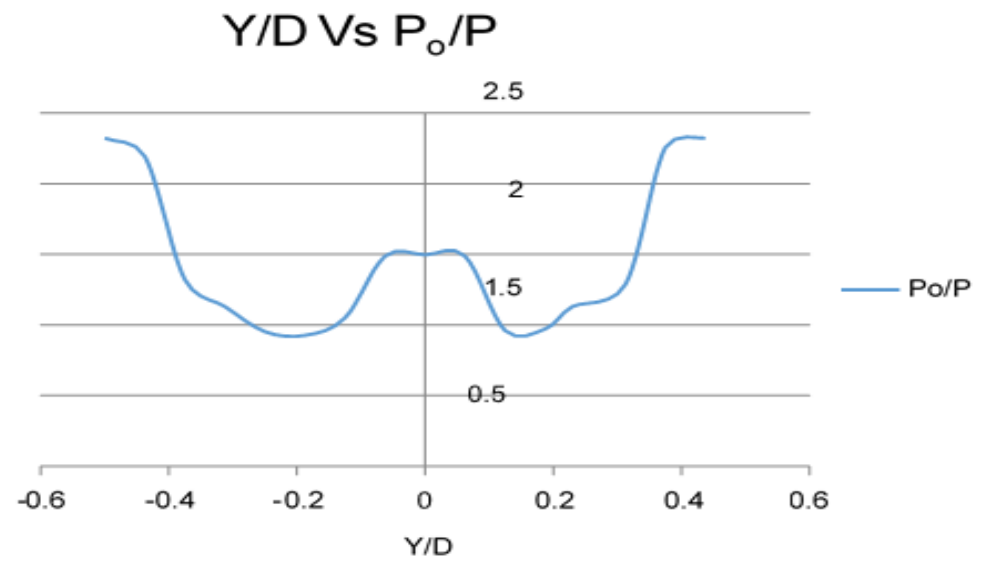

Figure 11 Radial pressure decay ( $\mathrm{Y}$ direction)

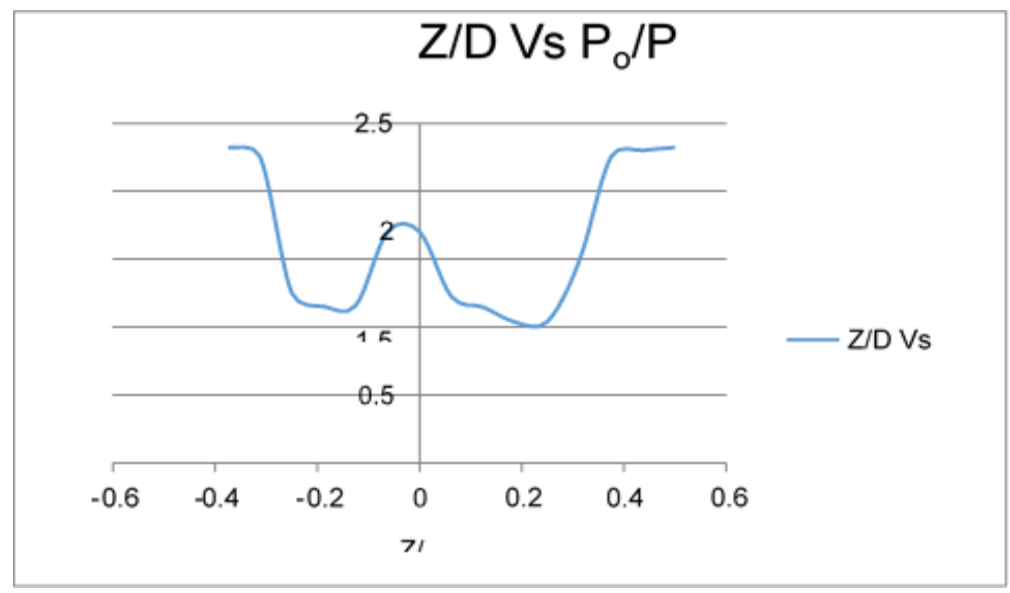

Figure 12 Radial pressure decay ( $\mathrm{Z}$ direction)

Fig.13 give the plots between the pressure ratio $\mathrm{Po} / \mathrm{P}-\mathrm{Y} / \mathrm{D}$ and $\mathrm{Z} / \mathrm{D}$ of the grooved nozzle. It shows the radial pressure decay of the nozzle in the $\mathrm{Y}$ and $\mathrm{Z}$ direction. The pressure ratio tends to decrease until the probe reaches the centre of the exit plane and then tends to increase. This is caused due to the increased distance between the nozzle exit plane and the pressure probe.

Fig.14 give the plots between the pressure ratio $\mathrm{P}_{\mathrm{o}} / \mathrm{P}-\mathrm{Y} / \mathrm{D}$ and $\mathrm{Z} / \mathrm{D}$ of the grooved nozzle. It shows the radial pressure decay of the nozzle in the $\mathrm{Y}$ and $\mathrm{Z}$ direction. The pressure ratio tends to decrease until the probe reaches the centre of the exit plane and then tends to increase. 
This is caused due to the increased distance between the nozzle exit plane and the pressure probe.
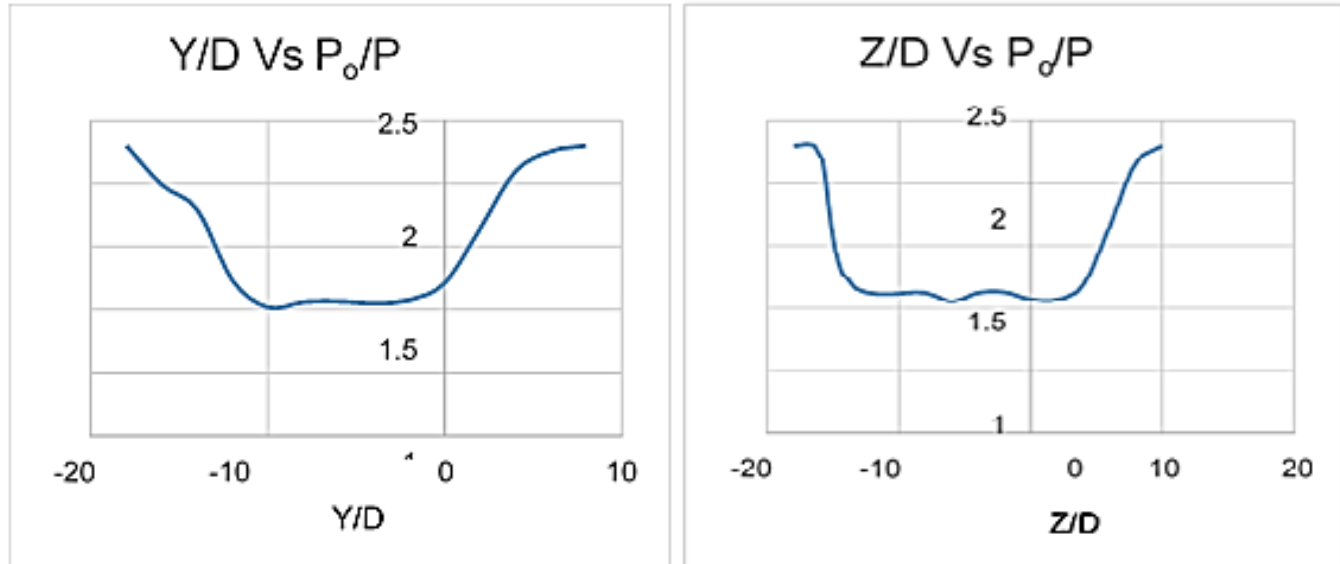

Figure 13 Radial pressure decay of grooved supersonic nozzle at 10mm from exit plan
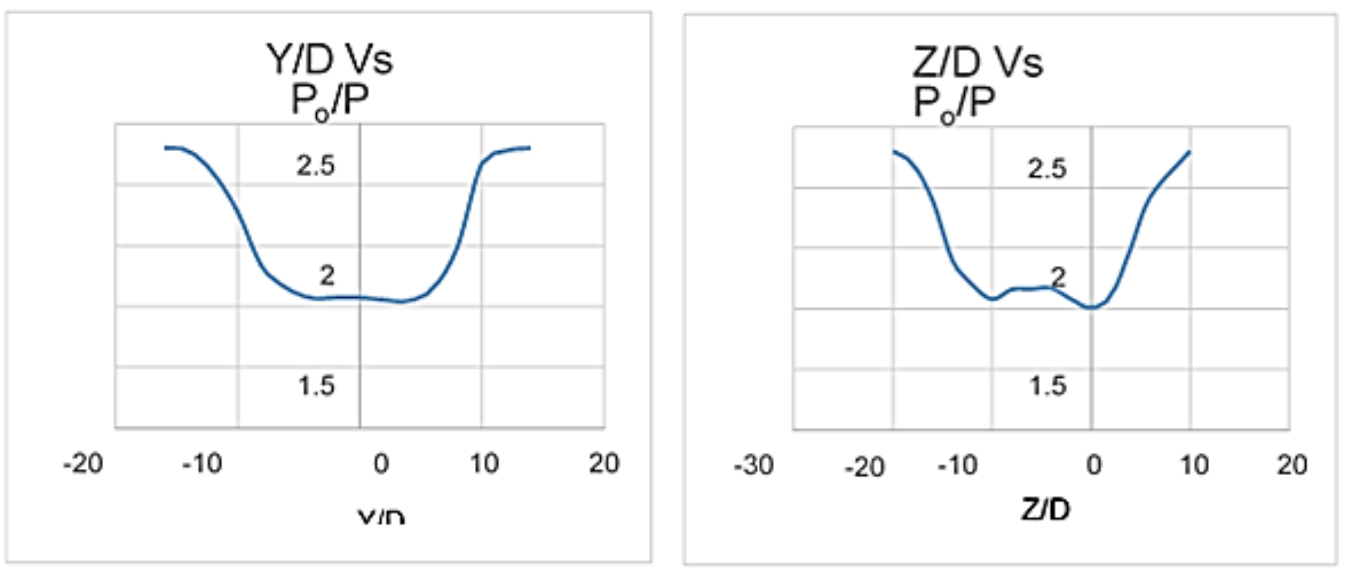

Figure 14 Radial pressure decay of grooved supersonic nozzle at $15 \mathrm{~mm}$ from exit plane

\subsection{Pressure Decay of Grooved Supersonic Nozzle at Successive Axial Locations - Y Direction}

Fig. 15 gives the comparison plot between the pressure ratio $\mathrm{P}_{\mathrm{o}} / \mathrm{P}$ and $\mathrm{Y} / \mathrm{D}$ of the grooved nozzle at different locations from the nozzle exit plane (at exit plane, $5 \mathrm{~mm}, 10 \mathrm{~mm}, 15 \mathrm{~mm}$ away). It shows the radial pressure decay of the nozzle in the $\mathrm{Y}$ and $\mathrm{Z}$ direction. The pressure ratio tends to decrease until the probe reaches the centre of the exit plane and then tends to increase. This is caused due to the increased distance between the nozzle exit plane and the pressure probe.

\subsection{Pressure Decay of Grooved Supersonic Nozzle at Successive Axial Locations - Z Direction}

Fig. 16 gives the comparison plot between the pressure ratio $\mathrm{P}_{\mathrm{o}} / \mathrm{P}$ and $\mathrm{Z} / \mathrm{D}$ of the grooved nozzle at different locations from the nozzle exit plane (at exit plane, $5 \mathrm{~mm}, 10 \mathrm{~mm}, 15 \mathrm{~mm}$ away). It shows the radial pressure decay of the nozzle in the $\mathrm{Z}$ direction. The pressure ratio tends to decrease until the probe reaches the centre of the exit plane and then tends to increase. This is caused due to the increased distance between the nozzle exit plane and the pressure probe. 


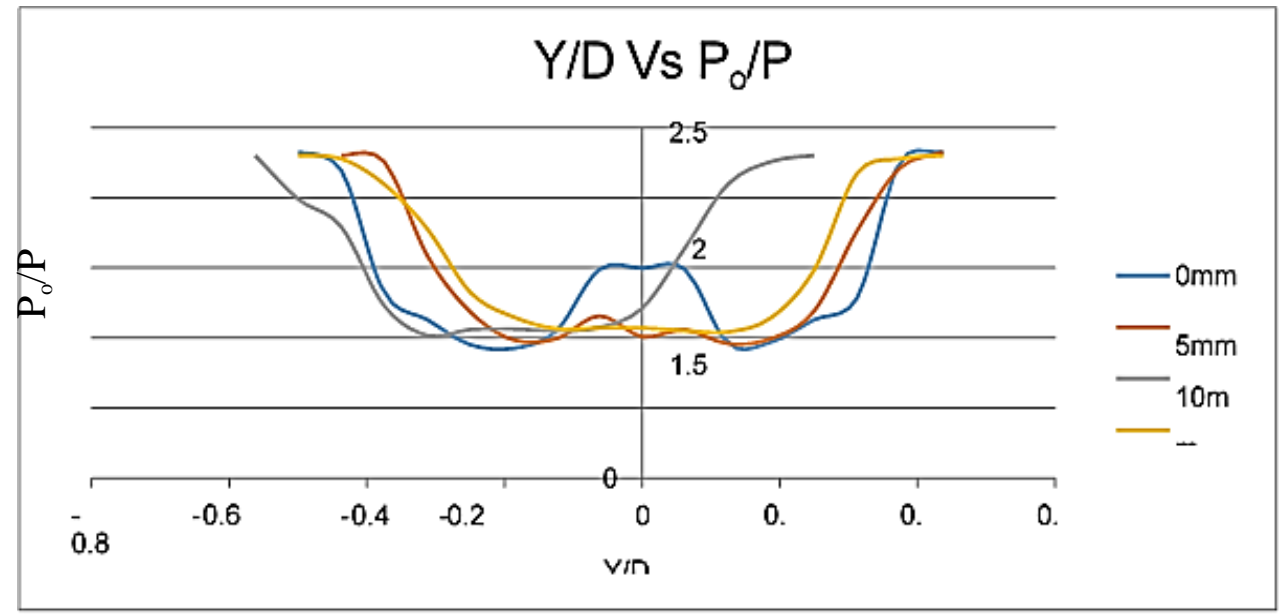

Figure 15 Radial pressure decay (Y direction)

\section{CONCLUSION}

The potential core length of the conventional nozzle is found to be $0.875 \mathrm{D}$ from its pressure decay characteristics plot. In the same method, the potential core length of the grooved nozzle is found to be $0.5 \mathrm{D}$. Therefore the decrease in core length is about $43 \%$, which is caused due to the introduction of ogival grooves. The reduction in potential core length directly leads to the reduction of jet noise. The turbulent interactions inside the core length acts as the main source of jet noise. Therefore, the use of grooved supersonic nozzle is found to be an effective method of noise suppression.

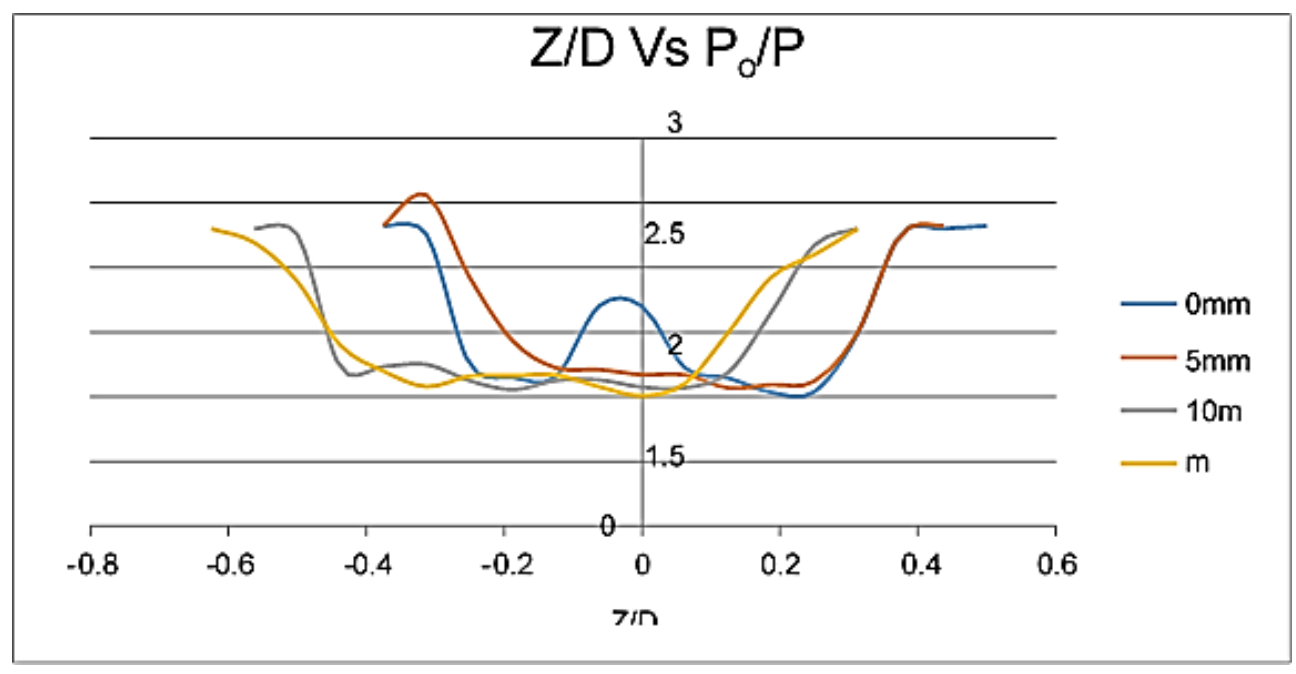

Figure 16 Radial pressure decay ( $\mathrm{Z}$ direction)

Also, the acoustic power levels produced by the conventional nozzle and the grooved nozzle are measured using the sound level meter app. The entire exercise is conducted at identical experimental conditions and the results are recorded. The acoustic power levels are measured at different locations such as at nozzle exit plane, $1 \mathrm{~m}, 2 \mathrm{~m}$ and $3 \mathrm{~m}$ from away it. The conventional nozzle produced $69 \mathrm{db}$ at the exit plane, $71 \mathrm{db}$ at $1 \mathrm{~m}, 70 \mathrm{db}$ at $2 \mathrm{~m}$ and $70 \mathrm{db}$ at $3 \mathrm{~m}$ from the exit plane. The grooved nozzle generated $68 \mathrm{db}$ at exit plane, $69 \mathrm{db}$ at $1 \mathrm{~m}, 68 \mathrm{db}$ at $2 \mathrm{~m}$ and $68 \mathrm{db}$ at $3 \mathrm{~m}$ from the exit plane. From the measurements, it is clear that the grooved nozzle produces about $\sim 3 \%$ reduction in jet noise. 
Decay Characteristics of Ogival Grooved Supersonic Nozzle: An Experimental Investigation

\section{REFERENCES}

[1] Nevis Jenifer G, Selva Preethi G (2016) "Numerical Analysis of Chevron Nozzle with Various Configurations for Noise Reduction", International Journal of Innovative Research in Science, Engineering and Technology, Vol. 5, Issue 5, May 2016.

[2] Dominic Xavier.D, R.Sarath Kumar And Kavitha G (2017) "Decay Characteristics Of A Supersonic Jet Issuing From C-D Nozzles With Triangular Grooves", International Jounal Of Mechanical Enginering And Technology, Vol 8, Issue 11, November 2017, Pp. 449-456.

[3] Rajashree V and Antony D T, "Design and Analysis of a Nozzle to Enhance Noise Suppression" International Journal of Advance Research and Development, Volume3, Issue3.

[4] Jayant Vishnu and E. Rathakrishnan, "Acoustic Characteristics of Supersonic Jets from Grooved Nozzles" Journal of propulsion and power, Vol. 20, No. 3, May-June 2004.

[5] Kowsalya P, "Experimental Study of Supersonic Jet Characteristics of a Grooved Nozzle," (IJMPERD), ISSN (P): 2249-6890; ISSN (E): 2249-8001, Vol. 10, Issue 3, Jun 2020, 8617 8624

[6] Grigore Cicon, "Aerodynamic noise control study of nozzles with triangular chevrons”, Applied Mechanics and Materials Vol. 436 (2013) pp 25-31

[7] Rathakrishnan, "Corrugated Tabs for Subsonic and Sonic Jet Control", J Aeronaut Aerospace Eng 2013, 2:5, DOI: 10.4172/2168-9792.1000120

[8] Ponnambalam MANIVANNAN, "Characteristic study of non-circular incompressible free jet" THERMAL SCIENCE: Year 2013, Vol. 17, No. 3, pp. 787-800.

[9] Xinran Li, "Experimental Investigation of Jet Flow Fields with Chevron Nozzles" IOP Conf. Series: Materials Science and Engineering 782(2020) 042010, doi:10.1088/1757899X/782/4/042010.

[10] S Ramu \& M Kannan, "Experimental and Analytical Comparison of Heat Transfer in Double Pipe Heat Exchanger” (IJAuERD) ISSN 2277-4785, Vol.2, Issue 2 Sep 2012 1-10. 